\title{
Dispatches from the front: emergency medicine teachers' perceptions of competency-based education
}

\author{
Glen Bandiera, MD, MEd*; David Lendrum, $\mathrm{MD}^{\dagger}$
}

\section{ABSTRACT}

Objectives: Controversy exists regarding the applicability of competency-based education during clinical rotations in emergency medicine (EM). Little has been written about the perceptions of front-line teachers regarding one such competencybased education paradigm, the CanMEDS framework. We undertook to determine 1) what perceptions exist among frontline teachers at two academic health science emergency departments (EDs) regarding the use of the CanMEDS roles to frame what residents should learn on ED rotations and 2) how those same teachers envision practically incorporating the CanMEDS roles into feedback provided to residents.

Methods: Teachers at two sites volunteered for a semistructured focus group study. Focus groups were moderated by an experienced qualitative researcher, and verbatim transcriptions were coded by two independent reviewers. The codes were merged into final themes. The final focus group was used to further explore issues raised and test assumptions made in the preceding groups.

Results: In five focus groups involving 21 participants, the Medical Expert and Professional roles were seen as most relevant to an EM rotation, whereas the Health Advocate, Manager, Scholar, and Collaborator roles were least relevant. On further exploration, however, faculty identified highly relevant components of each role that they could envision teaching in an ED. Participants also felt that the framework helped highlight the breadth of physician competencies and provided structure for teaching and feedback.

Conclusions: EM faculty find the CanMEDS framework helpful for structuring teaching and learning and that many elements of the roles, when defined, are feasible to integrate into a clinical rotation.

\section{RÉSUMÉ}

Objectif: L'applicabilité de la formation axée sur les compétences au cours des stages cliniques en médecine d'urgence est un sujet controversé. Peu de choses ont été écrites sur le point de vue des enseignants de première ligne sur le cadre de compétences CanMEDS, un modèle d'enseignement axé sur les compétences. Nous avons entrepris de déterminer 1) quel est le point de vue des enseignants de première ligne de deux services d'urgence d'un centre universitaire en sciences de la santé concernant I'utilisation des rôles CanMEDS pour encadrer I'apprentissage des résidents lors de leur stage clinique à l'urgence et 2) la façon dont ces enseignants envisagent l'intégration de ces rôles CanMEDS dans la rétroaction donnée aux résidents.

Méthode: Les enseignants de deux établissements ont accepté de participer à un groupe de consultation semistructuré. Les groupes de consultation étaient animés par un chercheur qualitatif d'expérience, et deux évaluateurs indépendants ont codé les transcriptions textuelles. Les codes ont été regroupés en thèmes. L'ultime groupe de consultation a servi à explorer plus en profondeur les questions soulevées et à tester les hypothèses avancées par les groupes précédents.

Résultats: Dans cinq groupes de consultation comprenant 21 participants, les rôles Expert médical et Professionnel ont été jugés les plus pertinents pour les stages à l'urgence, alors que les rôles Promoteur de la santé, Érudit et Collaborateur ont été jugés moins pertinents. Dans leur analyse plus détaillée, les enseignants ont toutefois cerné des éléments très pertinents de chaque rôle qu'ils pouvaient envisager d'enseigner dans un service d'urgence. Les participants étaient aussi d'avis que le cadre de compétences CanMEDS contribuait à mettre en évidence l'étendue des compétences des médecins et offrait une structure pour l'enseignement et la rétroaction.

Conclusion: Le corps professoral en médecine d'urgence est d'avis que le cadre de compétences CanMEDS est utile pour structurer l'enseignement et l'apprentissage et qu'il est possible d'intégrer de nombreux éléments des rôles dans un stage clinique, lorsqu'ils sont bien définis.

From the *Division of Emergency Medicine, Department of Medicine, St. Michael's Hospital, University of Toronto, Toronto, ON; and the †Department of Emergency Medicine, Calgary Regional Health Authority, Calgary, AB.

Correspondence to: Dr. Glen Bandiera, Division of Emergency Medicine, St. Michael's Hospital, Suite 1-008 Shuter Wing, 30 Bond Street, Toronto, ON M5B 1W8; bandierag@smh.toronto.on.ca.

This article has been peer reviewed. 
Keywords: assessment, competency-based education, daily encounter cards, faculty development, medical education

The Royal College of Physicians and Surgeons of Canada (RCPSC) implemented the CanMEDS 2000 physician training framework in 1996 and revised it in 2005..$^{1,2}$ Similar frameworks defining the basic competencies of specialist practice, such as the six Accreditation Council for Graduate Medical Education competencies and the Four Principles of Family Medicine as applied to College of Family Physicians of Canada (CFPC) emergency medicine (EM) programs, have evolved alongside CanMEDS., ${ }^{3,4}$ These widespread initiatives formally ushered in the era of competency-based education and called on teachers to incorporate a new perspective on postgraduate medical education. Since faculty members in Canadian emergency departments (EDs) typically teach residents from a multitude of residency programs, each with specialty-specific objectives, it becomes even more important that these faculty members understand what residents are to learn and receive feedback on. Education leaders have developed resources such as assessment tool inventories to support teachers in the application of these new concepts, but little has been published about front-line teachers' perceptions of the utility of the competency-based paradigms as educational resources. ${ }^{5,6}$

Members of each national RCPSC specialty committee in Canada are responsible for adapting the generic CanMEDS roles to their specific specialty. Residency program directors with the support of program committees are then required to adapt these competencies further to match local strengths, constraints, and educational philosophy. Finally, the goals and objectives in CanMEDS format must be developed for each rotation and educational component of the program. When distilled to this degree, the principles and educational theory underlying competency-based education risk being relatively obscure to the front-line teachers charged with implementing curricular changes. Previous research has demonstrated that teachers and learners both value most highly the content that they perceive to be relevant and specialty specific. ${ }^{7,8}$ Given that buy-in and deliberate teaching by front-line teachers in the clinical environment are still the mainstays of postgraduate medical education, successful implementation of competency-based models is contingent on making the CanMEDS constructs "real" and relevant to those same teachers and learners. Given that emergency physicians (EPs) encounter a significant breadth of the patient population, manage a diversity of clinical presentations, provide both general and specialist care, are often seen as a source of primary care, and assume some responsibility for the overall effectiveness of the ED team, all seven CanMEDS roles (Medical Expert, Communicator, Collaborator, Health Advocate, Manager, Scholar, and Professional) may seem intuitively to be relevant to their practice. In contradiction to this assertion, however, our previous work has shown that teachers are far more likely to provide feedback to residents on the Medical Expert and Professional roles than any of the other five roles.'

A successful competency-based program is predicated on the acceptance of formal program and rotation objectives, tailoring of those objectives to the needs and level of each individual resident, teaching around those same objectives, and assessing residents' performance in relation to the objectives in a psychometrically sound manner. To maximize an educational experience and allow teachers to tailor teaching to the learner, residents should be encouraged to develop their own personal learning objectives. ${ }^{7}$ Our previous work has shown that residents use multiple influences to inform their objective setting, including but not limited to program-derived goals and objectives, perceived personal needs, and the strengths of the rotation in question. ${ }^{10}$ For example, residents may prioritize or revise objectives based on accrued experience with some clinical presentations but not others or based on previous feedback about strengths and deficiencies. ED teaching studies have supported the notion of facilitated objective setting involving both teacher and learner. ${ }^{7,8}$ In other words, teachers and learners need to agree on learning objectives. Teachers are expected to understand the basis for rotation-specific objectives to help residents set their personal learning objectives and subsequently provide them with useful feedback. Furthermore, it is important that both residents and faculty perceive that the objectives reflect content that one would reasonably consider part of ED practice. The degree to which the objectives align between program, learner, teacher, and clinical milieu determines the likelihood of success in meeting these objectives. If programs are struggling to implement learning objectives based on the CanMEDS competencies without the full support and understanding of teachers and learners, this vital alignment will be compromised. 
Given the momentum behind competency-based frameworks in general and the particular use of the CanMEDS paradigm to inform accreditation standards for FRCP residency programs in Canada, it is important to understand how front-line teachers perceive the use of the CanMEDS competency-based framework as a contextually appropriate foundation for objective setting, teaching, and feedback in EDs. Specifically, we sought to determine 1) what perceptions exist among front-line teachers at two academic health science EDs regarding the utility and validity of using the CanMEDS roles to frame what various residents should learn on ED rotations and 2) how those same teachers envision practically incorporating the CanMEDS roles into feedback provided to residents from different programs.

\section{METHODS}

Faculty volunteers at two large, urban teaching EDs were solicited to take part in focus groups about the use of CanMEDS to inform teaching and assessment of postgraduate learners in the ED. The participants were given a small stipend for their time.

Each focus group was facilitated by an expert nonphysician with extensive experience in qualitative methods. The focus groups were semistructured, using leading questions derived by the investigators and pilot-tested on a group of three faculty teachers (who did not subsequently participate in the study) (see Focus Group Template, Appendix). We hoped to focus participants' thoughts specifically on the role of the EM rotation within the context of the overall residency experience yet not otherwise constrain them in their thinking about what they considered to be appropriate EM rotation objectives. For example, the focus group facilitator emphasized that an EM rotation may be the most appropriate place to learn some, but not all, physician competencies and, conversely, what should be taught in the ED is not necessarily the same thing as what is typically practiced there. In keeping with accepted qualitative methodology, the focus group moderator was enabled to explore issues at their discretion until full understanding was deemed to be obtained and subsequent focus groups were tailored to help validate or refute earlier experiences in previous focus groups. ${ }^{11}$

Verbatim transcripts were provided from direct recordings and manually coded using a grounded theory approach by two independent reviewers (G.B., D.L.). ${ }^{12}$ Grounded theory refers to a research method wherein the researchers do not attempt to validate a predetermined theory or idea but rather to use exploration itself (in this case, focus groups) to build a theory or develop possible explanations for a phenomenon. We employed a grounded theory approach to the data analysis (by allowing themes to emerge from the data rather than be driven by an a priori experience or hypotheses) but did not employ a full grounded theory method to the entire project (because we did not seek to establish a theory but rather to elaborate perceptions). The resulting codes were then used to prioritize the themes that were generated by the participants.

In keeping with grounded theory practice, the final focus group addressed some important themes that were identified in the previous sessions with a view to identifying what resources and approaches would best assist EM faculty in carrying out the teaching mandate. To further explore faculty perceptions of roles identified as less relevant and to determine if further exposure to the details of the role could affect those perceptions, the Manager role was chosen as a case study. Faculty had identified this role as having low applicability and a more abstract nature compared to other roles, making it one of the more challenging roles to implement. Although some basic quantitative analyses (eg, counting of themes, ideas, and references) were used to determine which issues were most prevalent in the data, qualitative analyses formed the primary basis for the descriptive results. To prevent misrepresentation of the strength of themes and sentiments in the data and respect the grounded theory approach (which accommodates variability and lack of standardization across focus groups), we deliberately chose a priori not to report frequency counts or other quantitative data.

Expressed written consent was obtained from all participants. This study received institutional ethics approval at both participating institutions.

\section{RESULTS}

Twenty-one participants completed five focus group sessions. All participants had full-time faculty appointments and were actively engaged in clinical teaching. At both sites, postgraduate learners are present on between 75 and $90 \%$ of clinical shifts. None of the 
participants had formal roles in the residency program other than clinical teaching at the time of the study; some but not all had significant nonclinical academic responsibilities. Group size varied from three to six, and the average duration of discussion was 75 minutes. We are satisfied that we achieved saturation of faculty perspectives because the themes in the third and fourth groups largely overlapped with those in the first two and no new themes emerged in the fourth group. In the fifth group, new ideas came about because of the shift in focus to verification and testing of concept, but no new themes arose in content related to the first four groups.

Faculty felt that the most applicable CanMEDS roles for resident education in a clinical EM practice environment were Medical Expert, Communicator, and Professional, with Health Advocate, Manager, Scholar, and Collaborator being of minimal applicability. Faculty were able to identify the following barriers to implementing the CanMEDS roles: lack of "buy-in" from trainees, lack of time, no observable "examples" of the roles, implicit teaching, difficulty in giving negative feedback, and the abstract nature of some roles. Although the last barrier may be specific to the CanMEDS roles as perceived at the outset of the study by the participants, the remainder of these barriers could quite reasonably apply to any new competency-based framework. We did not explore this possibility because we were less interested in comparing perceptions of CanMEDS to those of other paradigms than in perceptions about the concept of a competency-based model in general and of the mandated CanMEDS model in particular.

The benefits of the CanMEDS paradigm were felt to be increased awareness of the breadth of competencies expected of a specialist physician and a structure with which to frame feedback to learners. In a focused discussion about future steps, faculty felt that any objectives or expectations related to the roles would need to be tangible, observable, related to EM, and suitable for objective assessment. In spite of the initial perceptions that some roles are abstract, faculty were able to clearly identify concrete behaviour-based elements within all seven roles that they could envision teaching and assessing during a clinical shift.

\section{DISCUSSION}

This study demonstrates some important lessons about the perceptions that front-line teachers have about competency-based ED education and about processes that might best address the gap between educational theorists and teachers. Competency-based education is predicated on the development and acceptance of a structured, detailed set of assessable competencies. ${ }^{13}$ By defining core competencies and then deliberately planning where in a comprehensive curriculum these competencies are best taught (e.g., at the bedside versus in a workshop), competency-based frameworks may help define and clarify what is expected of learners in a clinical setting. As theorized in one 1999 overview:

Outcome-based education offers many advantages as a way of achieving this. It emphasises relevance in the curriculum and accountability, and can provide a clear and unambiguous framework for curriculum planning which has an intuitive appeal. It encourages the teacher and the student to share responsibility for learning and it can guide student assessment and course evaluation. ${ }^{14}$

Other reports, however, call into question the value and very foundation of competency-based education, referring to the complex nature of physician competence that cannot be fully "deconstructed" into core competencies and/or the lack of objective proof that competency-based education actually works. ${ }^{15,16}$ In spite of the widely held belief that physicians can learn what they need to learn by immersion in a clinical environment and assuming individual responsibility for staying up to date, emerging evidence supports the counterargument that physicians, like most other people, are very poor at assessing their own performance and learning needs. ${ }^{17}$ Ensuring that learners do actually learn and acquire key knowledge, skills, and attitudes, then, remains a mandate of the educational program and, by extension, the teachers within it. The common ground in these opposing views seems to be the recognition of the presence of a core body of knowledge, skills, and attitudes and a need for ongoing learning. The contentious issues at hand appear to be the degree to which physician competence can or should be broken down into definable "chunks" and whether CanMEDS is the right model. Our study demonstrates that although EPs tend to question the relevance of some of the CanMEDS roles, they do see value in the structure offered by the framework and can envision using the roles to frame feedback and teaching in the clinical context as long as the resulting objectives are tangible, concrete, and relevant to the clinical rotation and can be measured. 
In the RCPSC CanMEDS model, the seven specialist roles are framed using a five-level taxonomy. The "Definition" is a brief high-level statement about the overall focus of the role. The "Description" is a general summary of each component of the role and how it manifests in physician practice. The "Elements" are a list of behavioural and/or descriptive aspects of typical practice that exemplify the role. "Key Competencies" are statements of the major components of the role. Finally, "Enabling Competencies" are more detailed statements for each Key Competency and are phrased in behavioural terms that enable assessment of progress toward specialist-level competence. ${ }^{2}$ Program committee members then adapt specialty-specific CanMEDSbased goals and objectives to design rotation goals and objectives and assessment tools that cover the breadth of EM competencies.

Our study demonstrates that front-line teachers, who frequently are not involved in discussions of the CanMEDS paradigm at the program level or above, harbour significant reluctance and perceptions that may impede effective integration of the competencybased framework into clinical teaching. For example, the roles of Manager, Health Advocate, Collaborator, and Scholar were not seen as highly relevant to EM practice by participants. Participants felt that advocacy, as manifested by policy change, and population-based advocacy were not relevant or easily taught during an EM rotation. Likewise, aspects of the Manager role, such as functioning within the health care system and within an institution, were seen as abstract and not teachable. The Scholar competency was typically equated within our study to research and teaching, whereas the Collaborator competency was felt to mean teamwork, which was thought to be better taught by role modeling than by explicit instruction. These thoughts are supported by previous research wherein we found that the majority of comments provided to residents during feedback sessions were related to the Medical Expert and Professional roles. ${ }^{9}$ Such perceptions are sure to impede the efforts of even the most dedicated program director in increasing "uptake" of CanMEDS within their program and to tempt them to relegate most teaching of the roles to off-line token lectures (or equivalent) and abandon hope of connecting formal teaching to the clinical environment.

Based on these findings from early iterations of the focus groups, we decided to use an additional focus group to further explore participants' understanding of the roles. Participants were assigned one of the roles that were seen as least relevant by their colleagues in previous focus groups and were asked to review the complete summary of the role (Definition, Description, Key and Enabling Competencies, and Elements). Participants were then asked to report back to the group what, if anything, they felt were reasonable teaching content for an EM rotation. For all roles, participants were able to identify what they felt were highly relevant issues. For the Manager role, competencies related to managing surges in patient volume and quality assurance were seen as important issues for a clinical rotation in the ED. Likewise, within the Scholar role, the ability to ask critical questions and consult the literature on the fly were valued. For the Health Advocate role, the ability to access resources for individual patients and incorporate the presence or absence of risk factors into clinical decision making was seen as imperative. This final step in our methodology demonstrates that perceptions about the relevance of CanMEDS roles based on high-level labels and definitions may not be justified when consideration of more specific, operational-level aspects of the roles is undertaken.

The role of the teacher in clinical teaching and providing feedback to residents is critical to the development of competent, adaptable, and responsive EPs. Yet rotation-specific goals and objectives are left to program committee members to develop with due consideration to local needs, strengths, and constraints. The focus group model demonstrated in this study may provide a model whereby leaders in other programs might engage front-line faculty in understanding CanMEDS-based objectives tailored to their setting. Using local faculty members' perceptions about the overall utility of the CanMEDS framework to stimulate further discussion around the general and specialty-specific details of each role may enable program directors to increase engagement and minimize misconceptions and frustrations about what is expected from teachers. Our study provides some evidence that in doing this, faculty can see for themselves that CanMEDS is not as much of a foreign language as they may think.

\section{LIMITATIONS}

This exploratory study has several important limitations. First, although the study involved two academic 
health science centres, they were based at the same university and were core clinical sites for the same FRCP residency program. This might limit generalization of our findings to other teaching centres, which are often influenced by local culture and teaching traditions. This limitation is mitigated somewhat by the following: no faculty participants worked at both institutions; both sites had clearly different cultural milieus, one being an inner-city adult trauma centre serving a sociodemographically diverse community and the other a full-service trauma centre located in a more affluent, residential neighbourhood; and both sites had a mixture of FRCP and CCFP(EM) qualified faculty who had teaching experience ranging from less than 1 year to more than 20 years. We therefore feel that a robust diversity of opinion and perspective informed the focus group discussions.

A second limitation is the qualitative nature of the study. Qualitative research principles dictate that exploration of an idea should progress until saturation, defined as the time when no new information is forthcoming with incremental exploration. Furthermore, typical grounded theory models imply a search for an explanatory theory and a wholly organic approach to the research. Our approach can be termed a "limited" grounded theory approach in that we used a relatively fixed research method (semistructured focus groups with a predetermined population of participants) and did not seek to develop a theory per se but rather a full understanding of the issues related to competency-based education development in EM. We deliberately tried to integrate existing theory with the practicalities of teaching in a busy department with a view to designing an effective integration model for EM. Such is the challenge of medical education researchers so eloquently described by Albert and colleagues in a review of the roles of theory-driven education research and more practical, needs-driven research. ${ }^{18}$ Overreliance on the theoretical aspects of a problem limits applicability in the front-line setting, and focusing too much on the practical denies the ability to learn from and contribute to developing theory that underpins scholarly education planning. Our intent was to balance these often competing perspectives to bridge the gap between theory and practice. In doing so, we may have missed the opportunity to fully explore all possible perspectives on the issues (we did not interview learners, for example) or fully integrate our findings with existing educational theory. We feel justified in accepting this limitation given that our objective was to specifically determine faculty perceptions.

Finally, we chose to use the generic CanMEDS role descriptions for discussion rather than the specialtyspecific CanMEDS objectives of training for EM. We made this decision for two reasons: 1) the learners in the ED are from a multitude of specialties, and we felt it important to consider this breadth of learners in this study, and 2) we sought to determine the perceptions of faculty about the CanMEDS framework as it is usually described, that is, in general terms using the seven role titles. This latter point reflects a strength of the study by demonstrating the ability of faculty to recognize relevance.

\section{CONCLUSIONS}

EM teachers feel that some physician competencies are more applicable to their direct teaching context than others. Specifically, the Medical Expert, Communicator, and Professional roles were seen as highly relevant. Barriers to implementing broad competencies in the ED were related to learner buy-in, lack of tangible strategies, and lack of resources. Teachers desire tangible, objective, relevant learning objectives. EM educational leaders may benefit from incorporating faculty in planning rotation objectives and from using concrete elements of each role to inform the development of rotation-specific learning objectives and teaching materials.

Acknowledgements: This study was funded by a peer-reviewed CanMEDS educational grant from the Royal College of Physicians and Surgeons of Canada. The authors wish to thank Ms. Jane Tipping for her expertise with the focus groups and data acquisition.

Competing interests: None declared.

\section{REFERENCES}

1. Societal Needs Working Group. Skills for the new millennium. Ann RCPSC 1996;29:206-16.

2. Frank JR, editor. The CanMEDS 2005 physician competency framework. Better standards. Better physicians. Better care. Ottawa: The Royal College of Physicians and Surgeons of Canada; 2005. Available at: http://www.rcpsc.edu/ canmeds/CanMEDS2005/index.php. 
3. Accreditation Council for Graduate Medical Education Outcomes Project. Available at: http://www.acgme.org/ outcome/comp/compCPRL.asp (accessed March 19, 2009).

4. Standards for the accreditation of residency training programs. Mississauga (ON): The College of Family Physicians of Canada; 2006.

5. Toolbox of Assessment Methods. 2000 Accreditation Council for Graduate Medical Education (ACGME), and American Board of Medical Specialties (ABMS). Version 1.1. Chicago: ACGME; 2000. Available: http://www.acgme.org/ Outcome/assess/Toolbox.pdf.

6. Bandiera G, Frank J, Sherbino J. The CanMEDS assessment tools handbook. Ottawa: The Royal College of Physicians and Surgeons of Canada; 2005.

7. Bandiera GW, Lee S, Tiberius R. Effective teaching in the emergency department: how effective teachers get it done. Ann Emerg Med 2005;43:253-61.

8. Thurgur L, Bandiera G, Lee S, et al. What emergency medicine learners wish their teachers knew. Acad Emerg Med 2005;12:856-61.

9. Bandiera GW, Lendrum D. Daily encounter cards facilitate competency-based feedback but leniency bias persists. CFEM 2008;10:44-50.

10. Tenn-Lyn N, Bandiera G, Hodges B, et al. Factors influencing self-directed objective setting by off-service residents in emergency medicine. Ann Emerg Med 2008;51: 504.

11. Strauss A, Corbin J. Basics of qualitative research. Thousand Oaks (CA): Sage Publications; 1998.

12. Silverman D. Interpreting qualitative data: methods for analyzing talk, text and interaction. 3rd ed. Thousand Oaks (CA): Sage Publications; 2006.

13. Leung WC. Competency based medical training: review. BM7 2002;325:693-6.

14. Harden RM, Crosby JR, Davis MH. AMEE Guide No. 14: Outcome-based education: part 1-an introduction to outcome-based education. Medical Teacher 1999;21:7-14.

15. Talbot M. Monkey see, monkey do: a critique of the competency model in graduate medical education. Med Educ 2004;38:587-92.

16. Rees C. The problem with outcomes-based curricula in medical education: insights from educational theory. Med Educ 2004;38:593-8.

17. Davis DA, Mazmanian PE, Fordis M, et al. Accuracy of physician self-assessment compared with observed measures of competence — a systematic review. 7AMA 2006;296:1094102 .

18. Albert M, Hodges B, Regehr G. Research in medical education: balancing service and science. Adv Health Sci Educ 2007;12:103-15.

\section{APPENDIX: FOCUS GROUP TEMPLATE}

\section{Preamble (To be read by moderator)}

Thank you for agreeing to participate in this focus group discussion. We are recording this session to facilitate data analysis. The recording will be transcribed into text by a research assistant with no identifying information. We are interested in exploring your thoughts about addressing the CanMEDS roles during feedback sessions with learners. I am going to ask some questions to stimulate some discussion and I would like you to say whatever is on your mind about the topic, building on what your colleagues have said.

\section{General questions}

During the rotation, supervisors are expected to teach, observe, and evaluate the seven CanMEDS roles. What do you think about that?

Do you think that learners are exposed to all of the CanMEDS roles in the emergency department rotations?

How do you teach, evaluate, and comment on the roles during clinical shifts?

What are your thoughts on feedback to learners during clinical rotations? Is it easy? Worthwhile?

What do you think of the current shift feedback forms used to stimulate feedback to learners?

\section{Specific questions}

For EACH of the CanMEDS Roles, the group will be asked to consider the following:

Is this role appropriate to teach in the emergency department? To provide feedback on?

How frequently do you have the chance to address this role during a clinical shift?

How is this most commonly done?

How comfortable are you providing feedback about this role? How difficult is it to provide feedback about this role? What are the main impediments to providing effective feedback about this role? 